\title{
Periodic Points Under Iteration of Sum of Squares or Cubes of Digits in Some Positional Systems
}

\author{
Wenliang $\mathrm{Wu}^{\mathrm{a}}{ }^{*}$, Xingju Dang ${ }^{\mathrm{b}}$ and Yao Zhang ${ }^{\mathrm{c}}$ \\ College of Physics \& Electronic Information Engineering, Zhaotong University, China \\ azhsswwl@163.com, b1272256010@qq.com, '237763661@qq.com \\ * please mark the corresponding author with an asterisk
}

Keywords: black-hole number; iteration;sum of squares of digits;sum of cubes of digits; fixed point;periodic point;positional system;positive integer; formatting; style; styling; insert (key words) Abstract. There are different periodic and fixed points under iteration of sum of squares or cubes of digits of positive integer in different positional systems. On the iteration of sum of squares of digits, in binary and quaternary these points all converge to fixed point 1 . There are three fixed points and one 2-circle in ternary, three fixed points and one 3-circle in quinary, one fixed points and one 8 -scircle in senary, five fixed points and two 4-circles in septenary, three fixed points and two 2-circles and one 3-circle in octonary, three fixed points and one 2-circle and one 3-circle in nonary, one fixed point and one 6-circle in hexadecimal. On the iteration of sum of cubes of digits, in binary these points all converge to fixed point 1 . There are two fixed points and one 4-circle in ternary . There are only nine fixed points in quaternary. There are three points and one 3-circle in quinary, four fixed points and one 5-circle in senary, seven fixed points, four 2-circles, two 3-circles, one 4-circles and one 9-circlein septenary, six fixed points and one 5-circle in octonary, eight fixed points, two 2-circle, one 5-circle and one 11-circle in nonary, 24 fixed point, two 2-circles, one 3-circle, one 6-circle, two 10-circles, one 14-circle and one 15-circle in hexadecimal. The longest circle is found in base-14 and it is a 27-circle.

\section{Introduction}

Paper [1] introduced the black-hole numbers problem that is extensively paid close attention to in recent years. It considered black-hole numbers are essentially fixed points of natural numbers under some kind of iteration. Paper [1] also studied the fixed and periodic points under iteration of sum of biquadrates of digits and put forward that there are four fixed points, a pair of binary-period points and one group (seven) 7-period points for this iteration, through which, the probability that a positive integer fall into the fixed or periodic point is unbalanced and it mostly fall into 7-period point.

Paper [2] also introduced iteration of sum of squares of digits in the section of "happy number" $[2](P .234-235)$, which means the natural number falling into the fixed point 1 under iteration of sum of squares of decimal digits. Some problems are put forward : "If we replace squares by cubes, then the situation is dominated, at least in base $10 \ldots \ldots$ These converge to 370 , or to one of the 3 -cycles $(55,250,133)$ or $(160,217,352)$, or to one of the 2-cycles $(919,1459)$ or $(136,244)$, or, just occasionally, to 1 . What proportion goes to each? And what to the higher powers? And what for the different bases?"

From the study in Paper [1], we can conclude that the density of happy number is about $18 / 114=3 / 19$ under iteration of sum of squares. It is consistent with "It seems that about $1 / 7$ of all numbers are happy" in paper [2]. To cubic sum iteration, the proportions of seven cases are about: $7 / 500$ for that fall into $1,17 / 50$ for $153,9 / 50$ for $370,29 / 100$ for $371,23 / 500$ for $407,3 / 250$ for 2-circle (136,244 ), 13/500 for 2-circle (919,1459), 21/500 for 3-circle (160,217,352), 3/50 for 3 -circle $(55,250,133)$. The numbers that fall into 2 -circle $(136,244)$ are almost as rare as that fall into "black hole" 1 . Maybe the natural numbers that fall into 2-circle $(136,244)$ are "happier". Under iteration of sum of biquadrates, numbers that fall into "black hole"1 or "black hole" 1634 are similarly scarce and both their proportions are less than $0.2 \%$; Most natural numbers fall into 7-circle 
$(1138,4179,9219,13139,6725,4338,4514)$ and its proportion is about 90\%. ( Within 32806 , there are 1536 positive integers, in which any digit in high place is not greater than that in low place. )

\section{Iteration of sum of squares of digits}

Now we discuss the converging situation under iteration of sum of squares of digits in some positional numeral systems based on [1].

In binary, since sum of squares of digits for each 2-digit binary number is less than or equal to $1^{2} \times 2=2=10_{(2)}$, in other words, for each positive integers that are greater than 3 , its result of iteration must be less than itself by single iteration of sum of squares of binary digits. So only by calculation of natural numbers less than 3,we can find this iteration of every positive integer converge to the fixed point 1.

In ternary, since sum of squares of digits for each 2-digit ternary number is less than or equal to $2^{2} \times 2=8=22_{(3)}$, so only by calculation of positive integers less than 8 , we can find this iteration has three fixed points $1,5=12_{(3)}, 8=22_{(3)}$ and 2 -circle $(2,4)=(2,11)_{(3)}$. Each proportion of natural numbers falling into three fixed points is about $1 / 5$ and the proportion of falling into 2-circle is about $2 / 5$.

In quaternary, since $3^{2} \times 3=27=123_{(4)}$, so only by calculation of positive integers less than 27 , we know under this iteration, all positive integers fall into fixed point 1 . Within 27 , several natural numbers that have greater height are $21=111_{(4)}, 24=120_{(4)}$, and $27=123_{(4)}$. They all converge to 1 after iterating six times.

In quinary, since $4^{2} \times 3=48=143_{(5)}$, so calculating 23 positive integers within 48 , in which a digit in high place is not greater than that in low place, we know the iteration has three fixed points 1 , $13=23_{(5)}, 18=33_{(5)}$, and one 3 -circle $(4,16,10)=(4,31,20)_{(5)}$. Proportions for converging to four cases are about $5 / 23,6 / 23,1 / 12,10 / 23$ respectively. In it, natural numbers that converge to fixed point $18=33_{(5)}$ are the least. Within 44 , besides $18=33_{(5)}$, there is only one number $34=114_{(5)}$ in which high digit is not greater than the low one. Therefore, to the iteration of sum of squares of digits in quinary, the natural number falling into $18=33_{(5)}$ in the iteration may be called happy number.

In senary, since $5^{2} \times 3=75=203_{(6)}$, so calculating 35 positive integers within 75 , in which a digit in high place is not greater than that in low place, we know the iteration has a fixed point 1 and a 8-circle $(5,25,17,29,41,26,20,13)=(5,41,25,45,105,42,32,21)_{(6)}$

The proportion for converging to 1 is about $2 / 35$. Among the natural numbers within 71 , in which the high digit is not greater than the low one, besides number 1 , only one number:44=112 ${ }_{(6)}$ falls into 1 after iterating two times.

In septenary, since $6^{2} \times 3=108=213_{(7)}$, so calculating 48 positive integers within 108 , in which a digit in high place is not greater than that in a low place, we know the iteration has five fixed points: 1 , $10=13_{(7)}, 25=34_{(7)}, 32=44_{(7)}, 45=63_{(7)}$, and two 4-circles $(2,4,16,8)=(2,4,22,11)_{(7)},(13,37,29$, $17)=(16,52,41,23)_{(7)}$. Proportions for converging to seven cases are about 1/48, 11/48, 3/16, 1/48, $1 / 8,1 / 4,1 / 6$ respectively.

In octal, since $7^{2} \times 3=147=223_{(8)}$, so calculating 65 positive integers within 147 , in which a digit in high place is not greater than that in low place, we know the iteration has three fixed points: 1 , $20=24_{(8)}, 52=64_{(8)}$, two 2 -circles $(4,16)=(4,20)_{(8)},(13,26)=(15,32)_{(8)}$, and one 3 -circle $(5,25,10)=(5$, $31,12)_{(8)}$. Proportions for converging to six cases are about 1/13, 6/65, 2/65, 21/65, 11/65, 20/65 respectively.

In nonary, since $8^{2} \times 3=192=233_{(9)}$, so calculating 88 positive integers within 192 , in which a digit in high place is not greater than that in low place, we know the iteration has three fixed points: 1 , $41=45_{(9)}, 50=55_{(9)}$, one 2 -circle $(68,74)=(75,82)_{(9)}$, and one 3 -circle $(53,89,65)=(58,108,72)_{(9)}$. Proportions for converging to six cases are about 7/88, 3/88, 13/44, 19/88, 3/8 respectively.

In denary, we know the iteration has one fixed point 1 , and one 8 -circle $(4,16,37,58,89,145,42$, 20). Proportions for converging to two cases are about $3 / 19,16 / 19$ respectively.

In the undecimal positional notation system, since $10^{2} \times 3=300=253_{(11)}$, so calculating 144 positive integers within 300 , in which a digit in high place is not greater than that in low place, we know the 
iteration has three fixed points: $1,61=56_{(11)}, 72=66_{(9)}$, two 3 -circles $(5,13,25)=(5,12,23)_{(11)}$ and $(74$, $100,82)=(68,91,75)_{(11)}$. Proportions for converging to five cases are about $1 / 72,1 / 144,1 / 72,17 / 36$, $71 / 144$ respectively.

In dozenal, since $11^{2} \times 3=363=263_{(12)}$, so calculating 177 positive integers within 363 , in which a digit in high place is not greater than that in low place, we know the iteration has three fixed points: 1 , $29=25_{(12)}, 125=\mathrm{A} 5_{(12)}$, two 2 -circles $(5,25)=(5,21)_{(12)},(80,100)=(68,84)_{(12)}$, one 3 -circle $(20,65$, $50)=(18,55,42)_{(12)}$, and one 10 -circle $(34,104,128,164,66,61,26,8,64,41)=(2 \mathrm{~A}, 88, \mathrm{~A} 8,118,56$, $51,22,8,54,35)_{(12)}$. Proportions for converging to seven cases are about 2/177, 7/177, 2/59, 50/177, $6 / 59,21 / 177,73 / 177$ respectively.

In base-13, since $12^{2} \times 3=432=273_{(13)}$, so calculating 213 positive integers within 432 , in which a digit in high place is not greater than that in low place, we know the iteration has seven fixed points: $1,17=14_{(13)}, 45=36_{(13)}, 85=67_{(13)}, 98=77_{(13)}, .136=\mathrm{A} 6_{(13)}, 160=\mathrm{C}_{(13)}$, three 2-circles $(34,68)=(28$, $53)_{(13)},(100,130)=(79, \mathrm{~A} 0)_{(13)},(125,145)=(98, \mathrm{~B} 2)_{(13)}$. Proportions for converging to ten cases are about $5 / 71,6 / 71,4 / 71,11 / 213,2 / 213,1 / 213,10 / 213,23 / 213,72 / 213,49 / 213$ respectively.

In base-14, since $13^{2} \times 3=507=283_{(14)}$, so calculating 252 positive integers within 507 , in which a digit in high place is not greater than that in low place, we know the iteration has one fixed point: 1, one 2 -circle $(37,85)=(29,61)_{(14)}$, one 9 -circle $(25,122,164,221,123,185,178,244,46)=(1 \mathrm{~B}, 8 \mathrm{~A}$, $\mathrm{BA}, 11 \mathrm{~B}, 8 \mathrm{~B}, \mathrm{D} 3, \mathrm{CA}, 136,34)_{(14)}$. Proportions for converging to three cases are about 1/126, 43/252, $23 / 28$ respectively.

In base- 15 , since $14^{2} \times 3=588=293_{(15)}$, so calculating 294 positive integers within 588 , in which a digit in high place is not greater than that in low place, we know the iteration has three fixed points: 1 , $113=78_{(15)}, 128=88_{(15)}$, one 2 -circle $(145,181)=(9 \mathrm{~A}, \mathrm{C} 1)_{(15)}$, three 3 -circles $(2,4,16)=(2,4,11)_{(15)},(8$, $64,32)=(8,44,22)_{(15)},(201,205,269)=(\mathrm{D} 6, \mathrm{DA}, 2 \mathrm{E})_{(15)}$, one 5 -circle $(41,125,89,221,317)=(2 \mathrm{~B}$, $85,5 \mathrm{E}, \mathrm{EB}, 162)_{(15)}$, one 7 -circle $(20,26,122,68,80,50,34)=(15,1 \mathrm{~B}, 82,48,55,35,24)_{(15)}$, and one 9-circle $(74,212,200,194,340,150,100,136,82)=(4 \mathrm{E}, \mathrm{E} 2, \mathrm{D} 5, \mathrm{CE}, 7 \mathrm{~A}, \mathrm{~A} 0,6 \mathrm{~A}, 91,57)_{(15)}$. Proportions for converging to ten cases are about 1/49, 1/147, 1/294, 11/294, 9/98, 2/147, 22/147,, 41/147, 1/6, 34/147 respectively.

In hexadecimal, since $15^{2} \times 3=675=2 \mathrm{~A} 3_{(16)}$; so calculating 339 positive integers within 675 , in which a digit in high place is not greater than that in low place, we know the iteration has one fixed points 1 , and one 6 -circle $(13,169,181,146,85,50)=(\mathrm{D}, \mathrm{A} 9, \mathrm{~B} 5,92,55,32)_{(16)}$. Proportions for converging to two cases are about 94/339, 245/339 respectively.

The numbers of fixed and periodic points under iteration of sum of squares of digits on several positional systems mentioned above are listed in Table 1.

TABLE I. THE NUMBERS OF FIXED AND PERIODIC POINTS UNDER ITERATION OF SUM OF SQUARES OF DIGITS ON SEVERAL POSITIONAL SYSTEMS

\begin{tabular}{|c|c|c|c|c|c|c|c|c|c|c|}
\hline Base & $\begin{array}{l}\text { Numbers of } \\
\text { fixed points }\end{array}$ & $\begin{array}{l}\text { Numbers of } \\
\text { 2-circles }\end{array}$ & $\begin{array}{l}\text { Numbers of } \\
3 \text {-circles }\end{array}$ & $\begin{array}{l}\text { Numbers of } \\
4 \text {-circles }\end{array}$ & $\begin{array}{l}\text { Numbers of } \\
5 \text {-circles }\end{array}$ & $\begin{array}{l}\text { Numbers of } \\
\text { 6-circles }\end{array}$ & $\begin{array}{l}\text { Numbers of } \\
7 \text {-circles }\end{array}$ & $\begin{array}{l}\text { Numbers of } \\
\text { 8-circles }\end{array}$ & $\begin{array}{l}\text { Numbers of } \\
\text { 9-circles }\end{array}$ & $\begin{array}{l}\text { Numbers of } \\
10 \text {-circles }\end{array}$ \\
\hline 2 & 1 & & & & & & & & & \\
\hline 3 & 3 & 1 & & & & & & & & \\
\hline 4 & 1 & & & & & & & & & \\
\hline 5 & 3 & & 1 & & & & & & & \\
\hline 6 & 1 & & & & & & & 1 & & \\
\hline 7 & 5 & & & 2 & & & & & & \\
\hline 8 & 3 & 2 & 1 & & & & & & & \\
\hline 9 & 3 & 1 & 1 & & & & & & & \\
\hline 10 & 1 & & & & & & & 1 & & \\
\hline 11 & 3 & & 2 & & & & & & & \\
\hline 12 & 3 & 2 & 1 & & & & & & & 1 \\
\hline 13 & 7 & 3 & & & & & & & & \\
\hline 14 & 1 & 1 & & & & & & & 1 & \\
\hline 15 & 3 & 1 & 3 & & 1 & & 1 & & 1 & \\
\hline 16 & 1 & & & & & 1 & & & & \\
\hline
\end{tabular}

\section{Iteration of sum of Cubes of digits}

Now we discuss the converging situation under iteration of sum of cubes of digits in some positional numeral systems. 
In binary, since sum of squares of digits for each 2-digit binary number is less than or equal to $1^{3} \times 2=2=10_{(2)}$, in other words, for each positive integers that greater than 3 , its iterating result must be less than itself by single iteration of sum of cubes of binary digits. So computing only to natural numbers that less than 3 , we can obtain this iteration of every positive integer fall into the fixed point $1.1^{2} \times 2=2=10_{(2)}$, in other words, for each positive integers that are greater than 3 , its result of iteration must be less than itself by single iteration of sum of cubes of binary digits. So only by calculation of natural numbers less than 3 ,we can find this iteration of every positive integer converge to the fixed point 1.

In ternary, since sum of cubes of digits for each 2-digit ternary number is less than or equal to $23 \times 3=24=220_{(3)}$, so only by calculation of positive integers less than 24 , we can find this iteration has two fixed points $1,17=122_{(3)}$ and one 4-circle $(2,8,16,10)=(2,22,121,101)_{(3)}$. Proportions for converging to seven cases are about $3 / 8,1 / 8,1 / 2$ respectively.

In quaternary, since $3^{3} \times 4=108=1230_{(4)}$, so computing 27 positive integers which their a digit in higher position is less or equal than a lower one within 108 , we know has nine fixed points 1 , $8=20_{(4)}, 9=21_{(4)}, 28=130_{(4)}, 29=131_{(4)}, 35=203_{(4)}, 43=223_{(4)}, 55=313_{(4)}, 62=332_{(4)}$. Proportions for converging to nine cases are about $2 / 9,1 / 9,1 / 3,1 / 27,1 / 27,4 / 27,1 / 27,1 / 27,1 / 27$ respectively.

In quinary, since $4^{3} \times 4=256=2011_{(5)}$, so computing 54 positive integers which their a digit in higher position is less or equal than a lower one within 256 , we know the iteration has three fixed points $1,28=103_{(5)}, 118=433_{(5)}$, and one 3 -circle $(9,65,35)=(14,230,120)_{(5)}$. Proportions for converging to four cases are about $1 / 27,1 / 2,1 / 54,4 / 9$ respectively.

In senary, since $5^{3} \times 4=500=2152_{(6)}$, so computing 90 positive integers which their a digit in higher position is less or equal than a lower one within 500, we know the iteration has four fixed points 1 , $99=243_{(6)}, 190=514_{(6)}, 251=1055_{(6)}$, and one 5- circle $(9,28,128,62,73)=(13,44,332,142,201)_{(6)}$. Proportions for converging to five cases are about 44/90, 1/30,17/90, 1/45, 4/15 respectively.

In septenary, since $6^{3} \times 4=864=2343_{(7)}$, so computing 158 positive integers which their a digit in higher position is less or equal than a lower one within 864 , we know the iteration has seven fixed points: $1,9=12_{(7)}, 16=22_{(7)}, 133=250_{(7)}, 134=251_{(7)}, 152=305_{(7)}, \quad 250=505_{(7)}$, four 2-circles $(2,8)=(2,11)_{(7)},(91,217)=(160,430)_{(7)},(92,218)=(2,11)_{(7)},(244,496)=(466,1306)_{(7)}$, two 3-circles $(10,28,64)=(13,40,121)_{(7)},(36,126,72)=(51,240,132)_{(7)}$, one 4 -circles $(258,342,648,282)=$ $(516,666,1614,552)_{(7)}$, and one 9 -circles $(17,35,125,251,341,557,137,197,65)=(23,50,236$, $506,665,1424,254,401,122)_{(7)}$. Proportions for converging to 15 cases are about 3/79, 25/158, $3 / 158,2 / 79,1 / 79,1 / 79,1 / 79,5 / 158,8 / 79,9 / 79,7 / 79,4 / 79,8 / 79,6 / 79,25 / 158$ respectively.

In octal, since $7^{3} \times 4=1372=2534_{(8)}$, so computing 249 positive integers which their a digit in higher position is less or equal than a lower one within 1372, we know the iteration has six fixed points: $1,92=134_{(8)}, 133=205_{(8)}, 307=463_{(8)}, 432=660_{(8)}, 433=661_{(8)}$, and one 5 -circle $(434,440$, $559,469,476)=(662,670,1057,725,734)_{(8)}$. Proportions for converging to seven cases are about $59 / 249,9 / 83,4 / 249,1 / 83,5 / 83,5 / 249,136 / 249$ respectively.

In nonary, since $8^{3} \times 4=2048=2725_{(9)}$, so computing 364 positive integers which their a digit in higher position is less or equal than a lower one within 2048, we know the iteration has eight fixed points: $1,27=30_{(9)}, 28=31_{(9)}, 126=150_{(9)}, 127=151_{(9)}, 468=570_{(9)}, 469=571_{(9)}, 1052=1388_{(9)}$, two 2 -circles $(521,755)=(638,1028)_{(9)}, \quad(665,1025)=(818,1358)_{(9)}$, one 5-circle $(35,539,853,409$, $189)=(38,658,1147,504,230)_{(9)}$, and one 11-circle $(128,134,638,1198,470,476,980,540,432$, $152,856)=(152,158,778,1571,572,578,1308,660,530,178,1151)_{(9)}$. Proportions for converging to 12 cases are about 15/182, 5/26, 15/364, 3/364, 1/13,1/364, 15/364, 1/364, 2/91, 1/91, 23/364, $83 / 182$ respectively.

In denary, we know the iteration has five fixed points 1, 153, 370, 371, 407, two 2-circles $(136,244),(919,1459)$, and two 3 - circles $(160,217,352),(55,250,133)$. Proportions for converging to nine cases are about 7/503, 168/503, 91/503, 144/503 , 23/503,6/503, 13/503, 21/503, 30/503 respectively.

In the undecimal positional notation system, since $10^{3} \times 4=4000=3007_{(11)}$, so calculating 670 positive integers within 4000 , in which a digit in high place is not greater than that in low place, we know the iteration has eight fixed points: $1,35=32_{(11)}, 126=105_{(11)}, 370=307_{(11)}, 855=708_{(11)}$, 
$1161=966_{(11)}, 1216=\mathrm{A} 06_{(11)}, 1280=\mathrm{A} 64_{(11)}$, two 3-circles $(3,27,133)=(3,25,111)_{(11)}, \quad(9,729$, $243)=(9,603,201)_{(11)}$, one 4-circle $(433,307,1133,793)=(364,25 \mathrm{~A}, 940,661)_{(11)}$, two 6-circles $(435,459,1051,1071,1305,1855)=(366,388,876,894, A 87,1437)_{(11)},(687,593,1793,757,953$, $1415)=(575,49 \mathrm{~A}, 1390,629,797,1077)_{(11)}$, one 16 -circle $(36,54,1064,1536,688,684,476,1054$, $1584,10,1000,1520,226,946,1072,1366)=(33,4 \mathrm{~A}, 888,1177,576,572,3 \mathrm{~A} 3,879,1210, \mathrm{~A}, 82 \mathrm{~A}$, $1162,196,790,895,1032)_{(11)}$. Proportions for converging to 14 cases are about $4 / 670,5 / 670,178$ /670, 43/670, 42/670, 12/670, 9/670, 7/670, 19/670, 26/670, 40/670, 68/670, 114/670, 103/670 respectively.

In dozenal, since $11^{3} \times 4=5324=30 \mathrm{~B} 8_{(12)}$, so calculating 869 positive integers within 363 , in which a digit in high place is not greater than that in low place, we know the iteration has five fixed points: 1, $811=577_{(12)}, 944=668_{(12)}, 1539=\mathrm{A} 83_{(12)}, 2002=11 \mathrm{AA}_{(12)}$, one 3 -circles $(1001,1672,1738)=(6 \mathrm{~B} 5$, $\mathrm{B} 74,100 \mathrm{~A})_{(12)}$, and one 14 -circles $(8,512,755,1464,1008,343,415,1351,1136,1855,1344,793$, $342,288)=(8,368,52 \mathrm{~B}, \mathrm{~A} 20,700,247,2 \mathrm{~A} 7,947,7 \mathrm{~A} 8,10 \mathrm{~A} 7,940,561,246,200)_{(\mathbf{1 2})}$. Proportions for converging to seven cases are about 342/869, 1/869, 1/869, 19/869, 1/869, 7/869, 498/869 respectively.

In base-13, since $12^{3} \times 4=6912=31 B 9_{(13)}$, so calculating 1104 positive integers within 6912 , in which a digit in high place is not greater than that in low place, we know the iteration has five fixed points $1,793=490_{(13)}, 794=491_{(13)}, 854=509_{(13)}, 1968=B 85_{(13)}$, four 2-circles $(16,28)=(13,22)_{(13)}$, $(218,1028)=(13 \mathrm{~A}, 611)_{(13)},(277,577)=(184,355)_{(13)},(1675,3391)=(9 \mathrm{BB}, 170 \mathrm{~B})_{(13)}$, three 3-circles $(92,344,224)=(71,206,143)_{(13)},(161,1853,3071)=(C 5, A C 7,1523)_{(13)},(496,1744,1072)=(2 C 2$, $\mathrm{A} 42,646)_{(13)}$, three 4-circles $(532,1756,1126,1240)=(31 \mathrm{C}, \mathrm{A} 51,688,745)_{(13)},(1584,2124,2196$, $5184)=(94 \mathrm{~B}, \mathrm{C} 75, \mathrm{CCC}, 48 \mathrm{~A})_{(13)},(155,191,731,3059)=(\mathrm{BC}, 119,443,1514)_{(13)}$, one 6-circles $(9$, $729,129,2457,345,351)=(9,441,9 \mathrm{C}, 1170,207,210)_{(13)}$, and 11-circle $(141,2331,1065,1971$, $2355,1737,1539,855,1125,1071,405)=(\mathrm{AB}, 10 \mathrm{~A} 4,63 \mathrm{C}, \mathrm{B} 88,10 \mathrm{C} 2, \mathrm{~A} 38,915,50 \mathrm{~A}, 687,645$, $252)_{(13)}$. Proportions for converging to 17 cases are about 7/46, 1/276, 1/23, 4/1104, 1/1104, 1/138, 2/69, 5/1104, 5/1104, 51/552, 177/1104, 25/1104, 51/368, 185/1104, 5/1104, 27/368, 101/1104 respectively.

In base-14, since $13^{2} \times 4=8788=32 \mathrm{BA}_{(14)}$, so calculating 1378 positive integers within 8788 , in which a digit in high place is not greater than that in low place, we know the iteration has three fixed point: $1,244=136_{(14)}, 793=409_{(14)}$, one 3 -circle $(134,1241,1009)=(98,649,521)_{(14)}$, one 16-circle $(540,1520,1855,1288,728,1027,277,1457,560,1736,2240,1547,2414,2008,1243$, $1611)=(2 \mathrm{~A} 8,7 \mathrm{~A} 8,967,680,3 \mathrm{~A} 0,535,15 \mathrm{~B}, 761,2 \mathrm{C} 0,8 \mathrm{C} 0, \mathrm{~B} 60,7 \mathrm{C} 7, \mathrm{C} 46, \mathrm{~A} 36,64 \mathrm{~B}, 831)_{(14)}$, one 27-circle $(9,729,1028,368,1793,738,2027,2395,1756,2925,3926,433,2213,1396,1344,1944$, $4185,2605,2262,2186,1347,1971,2331,3402,153,3197,198)=(9,3 \mathrm{~A} 1,536,1 \mathrm{C} 4,921,3 \mathrm{AA}$, A4B, C31, 8D6, 10CD, 1606, 22D, B41, 71A, 6C0, 9CC, 174D, D41, B78, B22, 6C3, A0B, BC7, $1350, \mathrm{AD}, 1245,102)_{(14)}$. Proportions for converging to three cases are about 3/1378, 2/689, 25/1378, 33/1378, 455/1378, 429/689 respectively.

In base- 15 , since $14^{3} \times 4=10976=33 \mathrm{BB}_{(15)}$, so calculating 1763 positive integers within 10976 , in which a digit in high place is not greater than that in low place, we know the iteration has three fixed

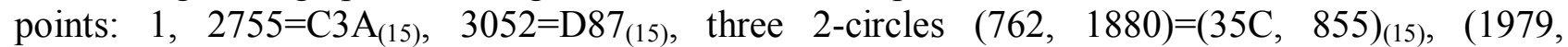
$4587)=(8 \mathrm{BE}, 155 \mathrm{C})_{(15)}, \quad(3599,5489)=(10 \mathrm{EE}, 195 \mathrm{E})_{(15)}$, one 5-circle $(1341,3085,4197,2485$, $2331)=(5 \mathrm{E} 6, \mathrm{DAA}, 139 \mathrm{C}, \mathrm{B} 0 \mathrm{~A}, \mathrm{~A} 56)_{(15)}$, one 8-circle $(397,1675,1559,5157,4269,3501,729$, $783)=(1 \mathrm{~B} 7,76 \mathrm{~A}, 6 \mathrm{DE}, 17 \mathrm{DC}, 13 \mathrm{E} 9,1086,339,373)_{(15)}$, one 13-circle $(277,371,2061,953,603$, $1035,793,2567,1555,3413,521,1403,755)=(137,19 B, 926,438,2 A 3,490,37 \mathrm{D}, \mathrm{B} 62,6 \mathrm{DA}, 1028$, 24B, 638, 355) $)_{(15)}$, and one 25-circle $(368,1242,2196,2276,2332,1468,2756,3086,4528,2324$, 3808, 4396, 578, 1032, 2304, 1756, 2072, 764, 2896, 3926, 1556, 3744, 1460, 684, 756) $=(198,57 \mathrm{C}$, 9B6, A1B, A57, 67D, C3B, DAB, 151D, A4E, 11DD, 1481, 288, 48C, A39, 7C1, 932, 35E, CD1, 126B, 6DB, 1199, 675, 309, 356) (15). Proportions for converging to ten cases are about 68/1763, 3/1763, 209/1763, 22/1763, 4/1763, 29/1763, 35/1763, 62/1763, 671/1763, 660/1763 respectively.

In hexadecimal, since $15^{3} \times 4=13500=34 \mathrm{BC}_{(16)}$; so calculating 2211 positive integers within 13500 , in which a digit in high place is not greater than that in low place, we know the iteration has 24 fixed points $1,35=23_{(16)}, 64=40_{(16)}, 65=41_{(16)}, 342=156_{(16)}, 371=173_{(16)}, 520=208_{(16)}, 584=248_{(16)}$, 
$645=285_{(16)}, 1189=4 \mathrm{~A} 5_{(16)}, 1456=5 \mathrm{~B} 0_{(16)}, 1457=5 \mathrm{~B} 1_{(16)}, 1547=60 \mathrm{~B}_{(16)}, 1611=64 \mathrm{~B}_{(16)}, 2240=8 \mathrm{C} 0_{(16)}$, $2241=8 \mathrm{C} 1_{(16)}, \quad 2458=99 \mathrm{~A}_{(16)}, \quad 2729=\mathrm{AA} 9_{(16)}, \quad 2755=\mathrm{AC} 3_{(16)}, \quad 3240=\mathrm{CA} 8_{(16)}, \quad 3689=\mathrm{E} 69_{(16)}$, $3744=\mathrm{EA}_{(16)}, 3745=\mathrm{EA}_{(16)}, 5614=15 \mathrm{EE}_{(16)}, \quad$ two 2-circles $(8,512)=(8,200)_{(16)},(72,576)=(48$, $240)_{(16)}$, one 3 -circle $(557,2213,1637)=(22 \mathrm{D}, 8 \mathrm{~A} 5, \mathrm{E} 49)_{(16)}$, one 6-circle $(1854,3114,2736,2331$, 2061, 2709) $=(73 \mathrm{E}, \mathrm{C} 2 \mathrm{~A}, \mathrm{AB} 0,91 \mathrm{~B}, 80 \mathrm{D}, \mathrm{A} 95)_{(16)}$, two 10-circles $(189,3528,4437,252,5103$, $6147,540,1737,2673,1344)=(\mathrm{BD}, \mathrm{DC} 8,1155, \mathrm{FC}, 13 \mathrm{EF}, 1803,21 \mathrm{C}, 6 \mathrm{C} 9, \mathrm{~A} 71,540)_{(16)},(191$, 4706, 233, 3473, 2927, 4922, 1055, 3440, 2540, 5201) $=(\mathrm{BF}, 1262$, E9, D91, B6F, 133A, 41F, D70, 9EC, 1451) $)_{(16)}$, one 14-circle $(730,3205,2365,2953,2572,2728,2512,2926,4291,1756,4141$, $2206,3985,4105)=(2 \mathrm{DA}, \mathrm{C} 85,93 \mathrm{D}, \mathrm{B} 80, \mathrm{~A} 0 \mathrm{C}, \mathrm{AA} 8,9 \mathrm{D} 0, \mathrm{~B} 6 \mathrm{E}, 10 \mathrm{C} 3,6 \mathrm{DC}, 102 \mathrm{D}, 89 \mathrm{E}, \mathrm{F} 91$, $\left.1_{1009}\right)_{(16)}$, and one 15-circle $(1001,3500,4925,2252,3968,3887,6758,1433,1583,3599,6119$, $3431,2756,2792,4256)=(3 \mathrm{E} 9$, DAC, 133D, 8CC, F80, F2F, 1A66, 599, 62F, E0F, 17E7, D67, AC4, AE8, 10A0) $(16)$, Proportions for converging to 32 cases are about 5/737, 9/737, 4/2211, 155/2211, 2/737, 23/2211, 7/2211, 3/737, 1/2211, 3/737, 157/2211, 17/2211, 5/2211, 1/737, 13/2211, 10/2211, 6/737, 127/2211, 1/2211, 14/2211, 22/2211, 8/2211, 13/2211, 1/2211, 10/737, 173/2211, 1/737, 25/737, 446/2211, 15/737, 512/2211, 215/2211 respectively.

The numbers of fixed and periodic points under iteration of sum of cubes of digits on several positional systems mentioned above are listed in Table 2 on the next page.

\section{Conclusion}

The Table 1 and 2 shows there are different fixed points and circles of iteration of sum of squares or cubes of digits on some positional systems.

On the iteration of sum of squares of digits, in binary and quaternary these points all converge to fixed point 1 . There are three fixed points and one 2-circle in ternary, three fixed points and one 3 -circle in quinary, one fixed points and one 8-scircle in senary, five fixed points and two 4-circles in septenary, three fixed points and two 2-circles and one 3-circle in octonary, three fixed points and one 2-circle and one 3-circle in nonary, one fixed point and one 6-circle in hexadecimal.

On the iteration of sum of cubes of digits, in binary these points all converge to fixed point 1. There are two fixed points and one 4-circle in ternary. There are only nine fixed points in quaternary. There are three points and one 3-circle in quinary, four fixed points and one 5-circle in senary, seven fixed points, four 2-circles, two 3-circles, one 4-circles and one 9-circlein septenary, six fixed points and one 5-circle in octonary, eight fixed points, two 2-circle, one 5-circle and one 11-circle in nonary, 24 fixed point, two 2-circles, one 3-circle, one 6-circle, two 10-circles, one 14-circle and one 15-circle in hexadecimal. The longest circle is found in base-14 and it is a 27-circle.

Through several sum iteration of squares or cubes of digital number on various positional systems, probabilities of every fixed or periodic points are unbalanced. It may be an interesting but difficult problem whether we can find the regularity of fixed points and circles of the iteration on different bases. 
TABLE II. THE NUMBERS OF FIXED AND PERIODIC POINTS UNDER ITERATION OF SUM OF CUBES OF DIGITS ON SEVERAL POSITIONAL SYSTEMS

\begin{tabular}{|c|c|c|c|c|c|c|c|c|c|c|c|c|c|c|c|}
\hline Base & 2 & 3 & 4 & 5 & 6 & 7 & 8 & 9 & 10 & 11 & 12 & 13 & 14 & 15 & 16 \\
\hline $\begin{array}{c}\text { Numbers of } \\
\text { fixed points }\end{array}$ & 1 & 2 & 9 & 3 & 4 & 7 & 6 & 8 & 5 & 8 & 5 & 5 & 3 & 3 & 24 \\
\hline $\begin{array}{c}\text { Numbers of } \\
\text { 2-circles }\end{array}$ & 0 & 0 & 0 & 0 & 0 & 4 & 0 & 2 & 2 & 0 & 0 & 4 & 0 & 3 & 2 \\
\hline $\begin{array}{c}\text { Numbers of } \\
\text { 3-circles }\end{array}$ & 0 & 0 & 0 & 1 & 0 & 2 & 0 & 0 & 2 & 2 & 1 & 3 & 1 & 0 & 1 \\
\hline $\begin{array}{c}\text { Numbers of } \\
\text { 4-circles }\end{array}$ & 0 & 1 & 0 & 0 & 0 & 1 & 0 & 0 & 0 & 1 & 0 & 3 & 0 & 0 & 0 \\
\hline $\begin{array}{c}\text { Numbers of } \\
\text { 5-circles }\end{array}$ & 0 & 0 & 0 & 0 & 1 & 0 & 1 & 1 & 0 & 0 & 0 & 0 & 0 & 1 & 0 \\
\hline $\begin{array}{c}\text { Numbers of } \\
\text { 6-circles }\end{array}$ & 0 & 0 & 0 & 0 & 0 & 0 & 0 & 0 & 0 & 2 & 0 & 1 & 0 & 0 & 1 \\
\hline $\begin{array}{c}\text { Numbers of } \\
\text { 8-circles }\end{array}$ & 0 & 0 & 0 & 0 & 0 & 0 & 0 & 0 & 0 & 0 & 0 & 0 & 0 & 1 & 0 \\
\hline $\begin{array}{c}\text { Numbers of } \\
\text { 9-circles }\end{array}$ & 0 & 0 & 0 & 0 & 0 & 1 & 0 & 0 & 0 & 0 & 0 & 0 & 0 & 0 & 0 \\
\hline $\begin{array}{c}\text { Numbers of } \\
\text { 10-circles }\end{array}$ & 0 & 0 & 0 & 0 & 0 & 0 & 0 & 0 & 0 & 0 & 0 & 0 & 0 & 0 & 2 \\
\hline $\begin{array}{c}\text { Numbers of } \\
\text { 11-circles }\end{array}$ & 0 & 0 & 0 & 0 & 0 & 0 & 0 & 1 & 0 & 0 & 0 & 1 & 0 & 0 & 0 \\
\hline $\begin{array}{c}\text { Numbers of } \\
\text { 13-circles }\end{array}$ & 0 & 0 & 0 & 0 & 0 & 0 & 0 & 0 & 0 & 0 & 0 & 0 & 0 & 1 & 0 \\
\hline $\begin{array}{c}\text { Numbers of } \\
\text { 14-circles }\end{array}$ & 0 & 0 & 0 & 0 & 0 & 0 & 0 & 0 & 0 & 0 & 1 & 0 & 0 & 0 & 1 \\
\hline $\begin{array}{c}\text { Numbers of } \\
\text { 15-circles }\end{array}$ & 0 & 0 & 0 & 0 & 0 & 0 & 0 & 0 & 0 & 0 & 0 & 0 & 0 & 0 & 1 \\
\hline $\begin{array}{c}\text { Numbers of } \\
\text { 16-circles }\end{array}$ & 0 & 0 & 0 & 0 & 0 & 0 & 0 & 0 & 0 & 1 & 0 & 0 & 1 & 0 & 0 \\
\hline $\begin{array}{c}\text { Numbers of } \\
\text { 25-circles }\end{array}$ & 0 & 0 & 0 & 0 & 0 & 0 & 0 & 0 & 0 & 0 & 0 & 0 & 0 & 1 & 0 \\
\hline $\begin{array}{c}\text { Numbers of } \\
\text { 27-circles }\end{array}$ & 0 & 0 & 0 & 0 & 0 & 0 & 0 & 0 & 0 & 0 & 0 & 0 & 1 & 0 & 0 \\
\hline
\end{tabular}

\section{Acknowledgment}

We thank Prof Daokun Kang very much for his support and help in this work.

\section{References}

[1] S. Zhaoshou, Z. Yao, W. Wenliang. The Periodic Points of Iteration of Each Digit's Biquadratic Sum of Natural Number. Journal of Chongqing University of Science and Technology(Natural Sciences Edition), 14(2012) 177-178.

[2] Richard Guy. Unsolved Problems in Number Theory. 2nd ed. New York: Springer Verlag, 1994.

[3] S. Kefu, W. Mingqiang. On the Sum of Each Digit's Square of Integer. Journal of Qufu Normal University(Natural Science), 25(1999) 45-46.

[4] L. Rong-hua, Z. Wei. Several Conclusions about Black-Hole Numbers. Journal of Changchun Teachers College, 24(2005) 24-26.

[5] S. Jianxin. Reverse-Conjugate Characteristic Numbers of Black-hole Numbers of Even Order. Journal of Shaoxing College of Arts and Sciences. 17(1997)16-20.

[6] H. Zhenguo. Feature of Black Hole Numbers and its magic generation. Journal of Guangxi University Wuzhou Branch, 14(2004) 62-64.

[7]Klaus E. Eldridge, Seok Sagong. The Determination of Kaprekar Convergence and Loop Convergence of All Three-Digit Numbers. Amer Math . Monthly,95(1988) 105-112.

[8]Z. Xueqian, L. Haipeng, H. Jiandong. The Study of R-transformational Black-hole Numbers. Journal of Guangxi Academy of Sciences, 24(2008) 1-3. 